\title{
AN UPDATE ON CURRENT STATUS OF INHERITED INTELLECTUAL DISABILITIES IN INDIA- AN OVERVIEW
}

\section{SANDIP HURPADE ${ }^{* 1}$ AND NEELAM KHAN ${ }^{2}$}

1: Research Scholar, Oriental University, Department of Pharmacy, Indore (M.P.)

2: Research Guide, Oriental University, Department of Pharmacy, Indore (M.P.)

*Corresponding Author: E Mail: Sandip Hurpade: hurpadess@gmail.com

Received $9^{\text {th }}$ May 2021; Revised 10 ${ }^{\text {th }}$ July 2021; Accepted 29 ${ }^{\text {th }}$ Aug. 2021; Available online $15^{\text {th }}$ Dec. 2021

https://doi.org/10.31032/IJBPAS/2021/10.12.1003

\begin{abstract}
In India, disabled people make up around 2 percent of the overall population. Information on the magnitude, level of disabilities, age at the start of disability, potential origin of disability, etc. is quite relevant in order to create an effective social inclusion plan for the disabled. The Persons with Disabilities Survey offers a database of the occurrence and prevalence of disabilities in the region, along with numerous other measures specific to persons with disabilities. For the preparation and decision making of persons with disabilities, statistical metrics extracted from a survey of persons with disabilities are needed. In present review, we have compared the results obtained by surveys of persons with disabilities conducted by National Statistical Office (NSO) from $15^{\text {th }}$ round July-1959 to latest $76^{\text {th }}$ round JulyDecember 2018. Disability prevalence in India (percentage of individuals with disabilities in Indian population) was $2.2 \%$. In rural regions, it was 2.3 per cent and in metropolitan areas, 2.0 per cent. Disability occurrence was greater among males than among females. For males, disability prevalence was 2.4 percent, which was 1.9 percent for females. The incidence of disability in the community, that is, the amount of individuals whose incidence of disability (by birth or otherwise) existed 365 days prior to the date of the study, was 86 per 1,00,000 persons. The survey findings are beneficial to numerous stakeholders such as the National Institution for the Transforming India (NITI Aayog), the Ministry of Social Justice and Empowerment, the Ministry of Health and Family Welfare, various Institutes/Organizations, the Economic and Social Commission for Asia and the Pacific (ESCAP) of the
\end{abstract}


United Nations and various researchers. By considering the present scenario, we have also highlighted the impact of COVID-19 on persons with intellectual disability. Individuals with intellectual disability experiences with the pandemic must be elicited in order to comprehend the effects on their life and how they have saved themselves from infections.

\section{Keywords: Intellectual Disabilities; India; COVID-19, NSSO; NSO $76^{\text {th }}$ round}

\section{INTRODUCTION}

In India, disabled people make up around 2 percent of the overall population. Information on the magnitude, level of disabilities, age at the start of disability, potential origin of disability, etc. is quite relevant in order to create an effective social inclusion plan for the disabled [1]. Intellectually disabled people have slow intellectual progress, below average academic achievement, and ability deficiencies such as speech, social abilities, and self-help skills. Intellectual disabilityis a disorder in which behavioral growth from infancy or early childhood is slightly belowaverage [2]. Age-appropriate intellectual and adaptive conduct is greatly limited and it is a permanent disorder and rarely a time-limited condition. Such kids are sluggish to meet developmental milestones faster than regular kids. In certain people with developmental disabilities, the areas of the brain that are not affected begin to evolve. Therefore, as they get older, they begin to learn talents and abilities [3]. It is also stated that brain injury induces a sort of a pause in growth that causes ability deficits. If training assistance is expanded in early years and relations between home and school are sufficiently reinforced, therefore training results continue over a longer period of time. Intellectual deficiency is not a disorder of the brain [4]. At every age, mental disorder may arise, although intellectual impairment has been present since childhood. However, psychiatric disorder can often occur in certain persons with intellectual disabilities, and may be the product of a behavioral, psychological or biological impairment in the person and may be treated with comprehensive therapy $[\mathbf{1}, \mathbf{2}]$.

Mental disorder is characterized by changes in perception, disposition or actions combined with depression and diminished performance, according to the US Department of Health and Human Services. At one point, it may apply to one or more psychiatric illnesses. A major public health issue is mental disease [5]. One out of four (25 per cent) people were afflicted by a type of psychiatric disease, according to the 
World Health Organization (WHO). In developed economies, the incidence of mental illnesses is smaller, but in emerging nations, the worldwide rate of chronic mental illness is larger [4, 6]. Eighty percent (80 percent) of the mentally disabled community reside in countries with low and middle incomes. The existence of mental disorder does not only impact the client and his intimate, social, educational and professional life, but also causes detrimental effects for his whole family [7].

India has 17.5 percent of the world's population, it is believed that the amount of individuals suffering from mental disorder is high. It is incredibly necessary for India to provide a true estimation of the nation's number or incidence of mental illnesses [8, 9]. There have been many determinants of mental disease reported thus far. Poverty, genetic and environmental factors: Adolescent trauma and violence are common partners in the nation's psychiatric illnesses. Mental disability distribution often differs with age, social class, ethnicity and rural and urban environments. People in rural deprived areas have greater mobility and affordability barriers in seeking professional support relative to urban environments. Intellectual impairment may occur if anything interferes with natural brain growth $[\mathbf{1 0}, \mathbf{1 1}]$. The most important causes of intellectual impairment are represented in Figure 1.

In infants, because of behavioral and emotional disorders, the incidence of mental disease is greater. This are also attributed to behavioral stress, inadequate parenting and education, whereas age-related dementia and other cognitive conditions escalate with age [12]. The essence of medical and psychological service needs often differs, since behavioral conditions differ with age. In order to prepare and offer care, the incidence of mental disorders correlated with age is quite significant. In rural locations, a high proportion of the Indian population has considerably higher poverty rates than in urban areas [13, 14]. Since poverty is a significant social determinant of mental illness, it is therefore crucial to research the disparities in occurrence between rural and urban areas in order to prepare and improve programs for the community. The Persons with Disabilities Survey offers a database of the occurrence and prevalence of disabilities in the region, along with numerous other measures specific to persons with disabilities. For the preparation and decision making of persons with disabilities, statistical metrics extracted from a survey of persons with disabilities are needed $[7, \mathbf{1 2}, \mathbf{1 3}]$. In present review, we have compared the results 
obtained by surveys of persons with disabilities conducted by National Statistical Office (NSO) from $15^{\text {th }}$ round July-1959 to latest $76^{\text {th }}$ round July-December 2018. The survey findings are beneficial to numerous stakeholders such as the National Institution for the Transforming India (NITI Aayog), the Ministry of Social Justice and Empowerment, the Ministry of Health and Family Welfare, various
Institutes/Organizations, the Economic and Social Commission for Asia and the Pacific (ESCAP) of the United Nations and various researchers. By considering the present scenario, we have also highlighted the impact of COVID-19 on persons with intellectual disability. Some common forms of intellectual disabilities are illustrated in Figure 2.$$
\text { Family various }
$$

(n)




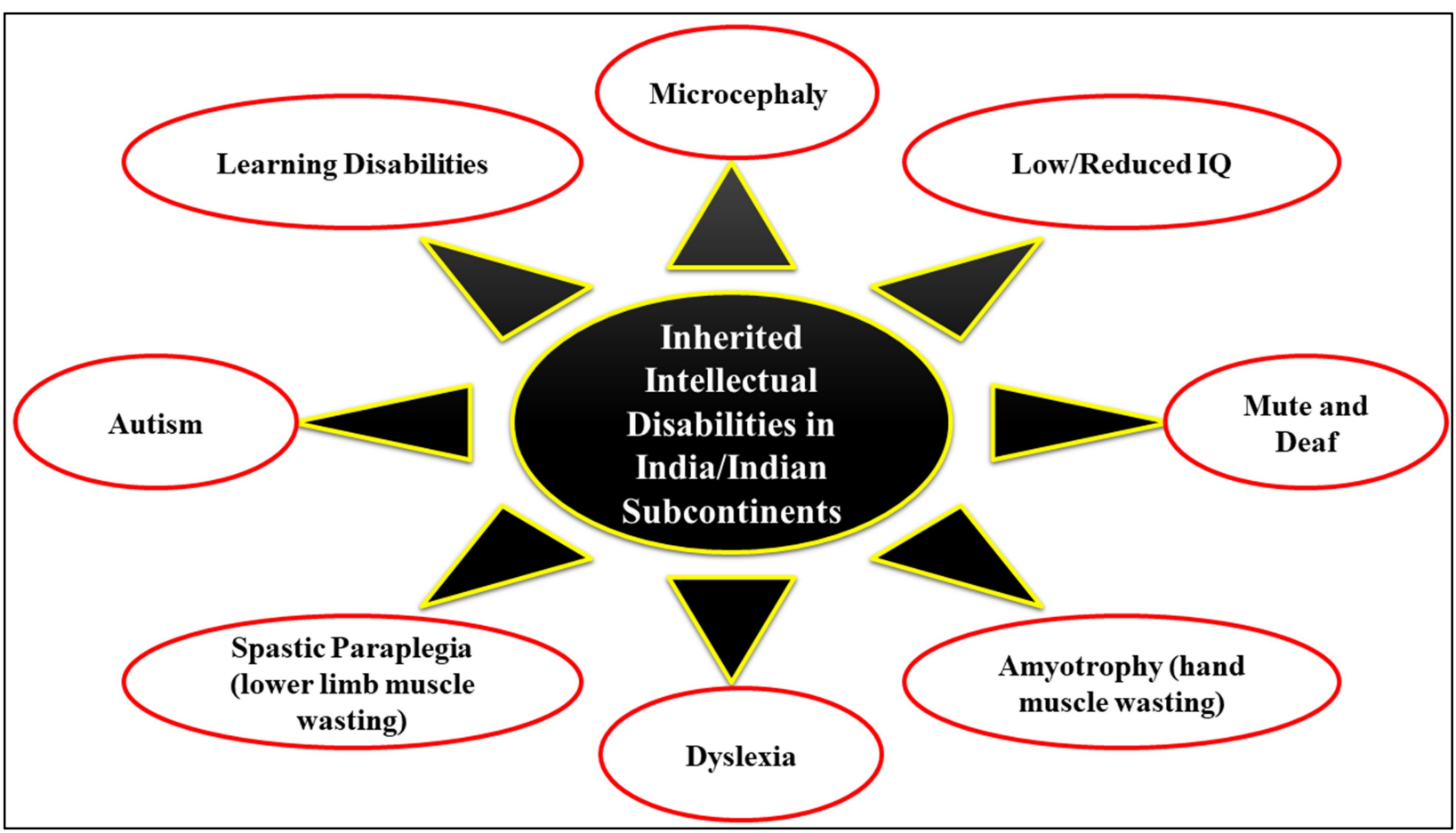

Figure 2: Some common forms of intellectual disabilities in India/Indian subcontinents

2. HISTORY OF STUDIES OF PEOPLE WITH DISABILITIES UNDERTAKEN BY THE NATIONAL STATISTICAL OFFICE (NSO)

The NSO made first ever effort to obtain details on the people with disabilities in the $15^{\text {th }}$ round between July 1959 and June 1960. The inquiry was exploratory in nature and was limited to rural areas only. However, in the $16^{\text {th }}$ round (July 1960-June 1961), the regional coverage was expanded to metropolitan areas. The topic was again dealt with in the $24^{\text {th }}$ (July 1969-June 1970) and $28^{\text {th }}$ (October 1973-June 1974) cycles of the National Service Scheme (NSS).

In the second half of 1981, the NSO carried out a detailed study of people with disabilities in its $36^{\text {th }}$ round. After a 10-year delay, a second impairment study was performed in the $47^{\text {th }}$ round between JulyDecember 1991. The basic structure of these surveys, i.e. definitions, concepts and operating procedures, stayed the same. Input was obtained from all people with one or more of the three physical disabilities-visual, communication (i.e. listening and/or speech) and locomotive. Disability details, such as form of disability, cause, age at the onset of disability, type of aid/appliance used, etc., were collected along with certain social and economic characteristics.

Once again, following a break of eleven years, the third study on the disabled was carried out in the 58th round between 
July-December 2002. In this phase, scope has now been expanded to involve cognitive disabilities, retaining the other terms, meanings and practices for physical disability as in the $47^{\text {th }}$ series. In addition to the specifics of physical and mental conditions, the socio-economic features of people with disabilities, such as their age, literacy, occupational qualifications, job, origin of disability, age at the advent of disability, etc., have been collected [15].

\section{DISABILITY STUDY PERFORMED} BY NATIONAL SAMPLE SURVEY ORGANIZATION NSS $\mathbf{5 8}^{\mathrm{TH}}$ ROUND (JULY-DECEMBER 2002)

In its endeavour to include details on the severity and other features of persons with disabilities, the National Sample Survey Organization (NSSO) undertook the third survey of persons with disabilities in the country between July-December 2002 [Report No. 485 (58/26/1)](16).This report contains, for the first time, statistics on individuals with emotional disorders, along with information on individuals with physical disabilities. Mental disorder information for people with mental retardation and mental impairment is given. Visual, auditory, voice and locomotor disorders are among the physical disabilities covered during the study and the conclusions presented in the research.
The study explains the prevalence and occurrence of various types of impairment and the distribution of disabled persons by reason of disability, marital status, standard of schooling, living situation, status of activity, etc.

45571 and 24731 households with at least one disabled individual, chosen from 4637 villages and 3354 urban blocks, respectively, were surveyed at the all-India level. In rural and urban India, the number of disabled people reported was 49,300 and 26,679 , respectively. Of the overall projected households in rural and urban India, about 8.4 percent and 6.1 percent reported getting at least one disabled person, respectively. In both fields, the average size of these households was calculated at 5.7, which was slightly greater than the average size of households in general. Over the duration from July to December 2002, the number of disabled people in the world was reported at 18.49 million. Around $1.8 \%$ of the total population was generated by them. About 10.63 percent of individuals with disabilities suffer from more than one form of disability. There were 1755 for every 100,000 persons in India who were either psychologically or physically impaired. The incidence of impairment among rural residents was 1.85 per cent and that of urban residents was 1.50 
per cent. The average for men was 2.12 and 1.67 percent, while for women in rural and urban India, respectively, it was 1.56 and 1.31 percent. The prevalence of locomotor deficiency was higher in the nation among the multiple categories of disabilities, 1046 in the rural and 901 in the urban per 100,000 people. Vision impairment and auditory disability preceded this. Over the last 365 days, approximately 69 individuals in 100,000 have either been born disabled or been disabled in India for whatever causes. It was also found that the occurrence rate among males was greater than that among females. Around 84 percent of people with mental retardation and 82 percent of those with speech disorders were born with disabilities. They also developed disability over the course of life with those with other forms of disability, and it is largely correlated with the aged. About 13\% of the mentally impaired were considered to be significantly disabled and even with aid/appliance they did not take self-care. Approximately $47 \%$ of the disabled have never been married. For the mentally retarded, the condition is worse. Around 55\% of the disabled in India were illiterate and around 9\% had achieved secondary and higher education levels. Just 15 to 35 out of 1000 people with disabilities pursued any vocational course and 74 to 80 percent of them completed a non-engineering course. On both fields, the existing enrolment level per 1,000 disabled people aged 5-18 years in ordinary school was higher in rural than in urban schools-475 and 444, respectively. About $11 \%$ of people with disabilities aged 5-18 years were registered in special schools in metropolitan regions, contrasted with less than $1 \%$ in rural areas. About $26 \%$ of disabled individuals are working. At 6 percent, the proportion of working among the mentally retarded was the lowest. Before the advent of disabilities, approximately 37 percent of the disabled (age $5+$ ) as a whole were employed. The study shows that approximately $3 \%$ of people with disabilities lived independently and 5\% just lived with their family [16].

\section{PRESENT DISABILITY STUDY PERFORMED DURING THE NSS $7^{\text {TH }}{ }^{\text {ROUND (JULY-DECEMBER 2018) }}$}

At its $94^{\text {th }}$ meeting held on 29 May 2017, the National Statistical Commission (NSC) agreed that Disability, Drinking Water, Sanitation, Hygiene and Housing Status should be the focus of the NSS $76^{\text {th }}$ round (July-December 2018) [15]. The Working Group was established under the chairmanship of Dr. Partha Mukhopadhyay, Senior Fellow, Centre for Policy Analysis, 
New Delhi, for the 76th round of the NSS.

Bearing in mind the overall dimensions of data collection, the existing consumer need for data and the relevance of the survey findings, the NSS $76^{\text {th }}$ round Working Group suggested certain adjustments to the layout of the survey schedule by changing the questions asked to recognize people with disabilities, incorporating related things to the survey schedule, etc. The surveys of persons with disabilities conducted by National Statistical Office (NSO) are depicted in Figure 3.

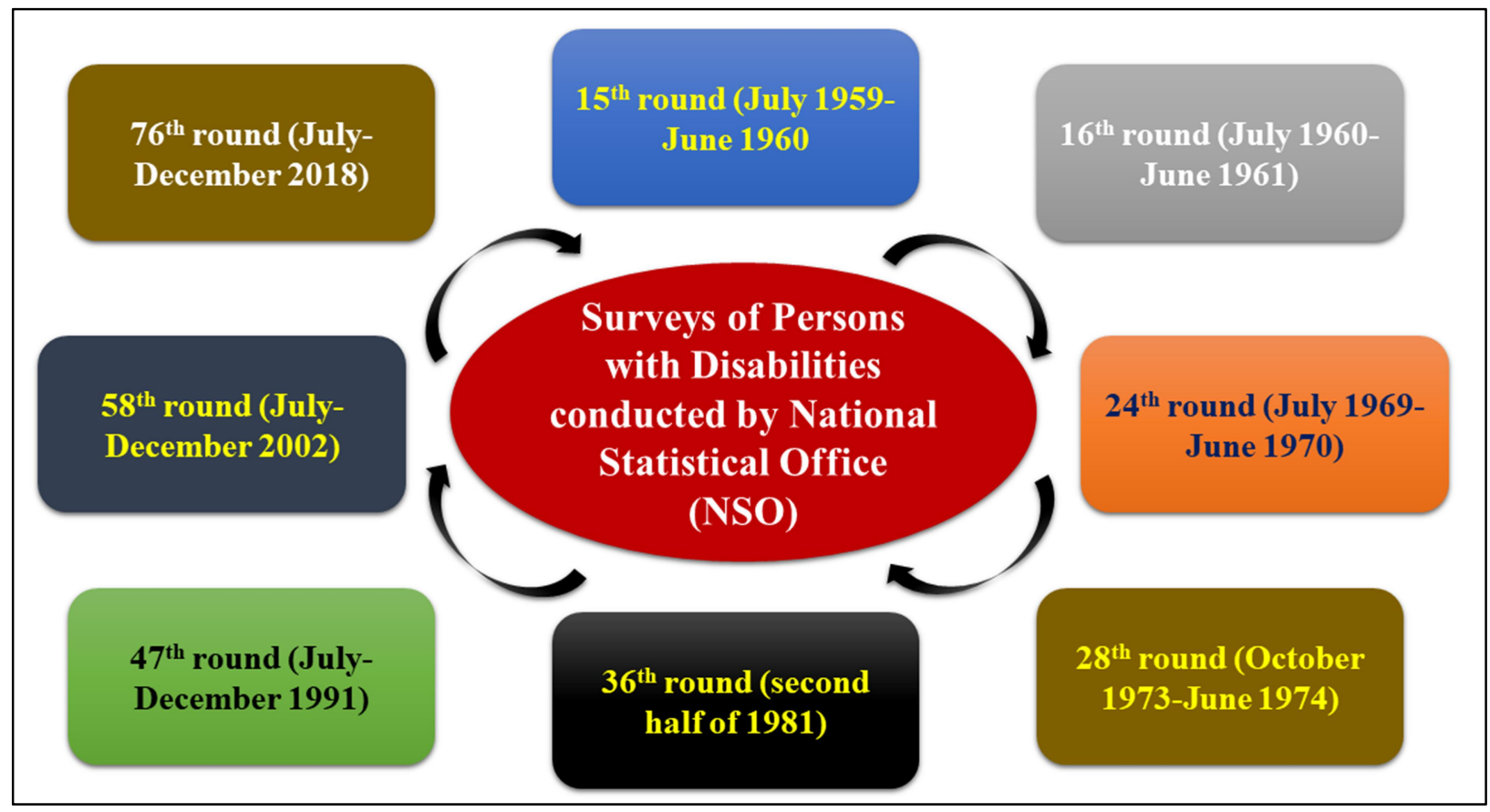

Figure 3: The surveys of persons with disabilities conducted by National Statistical Office (NSO)

Some of the significant features of the NSS $76^{\text {th }}$ Round Survey of Individuals with Disabilities are listed below. 1) In Schedule 26, allowance was rendered for the registration of people with disabilities pursuant to the classification used in the 2016 Rights of Persons with Disabilities Act (PWD Act) 2016; 2) For people with disabilities, statistics is gathered on the challenges experienced in accessing/using public transit and in accessing/using public buildings; 3) For people with disabilities, details was obtained about whether or not to have a disability certificate and a percentage of disability as per certificate; 4) For people with disabilities, details about the availability of a regular care professional has been collected; 5) Data on out-of-pocket impairment costs has been reported; 6) Information on enrolment of school has been 
obtained for people with disabilities in the age range 3 to 35 years; 7) For each family member with disabilities, jobs and unemployment data has been compiled in regular circumstances; 8) For each family member aged 12 to 59 years with disabilities, information was obtained about whether to receive/receive vocational/technical training. In addition, additional details on the area of training, length of training, method of training, source of support for training, etc. has been obtained for those who have undergone structured vocational/technical training [15].

\section{GOAL OF THE NSS $76^{\mathrm{TH}}$ ROUND} SURVEY FOR PEOPLE WITH DISABILITIES (JULY- DECEMBER 2018)

The key aim of the NSO $76^{\text {th }}$ round survey was to approximate indices of frequency and prevalence of disability, origin of disability, age at start of disability, services for people of disability access, difficulties in the access/use of public building and public transit for individuals with disabilities [15].
6. THE STATISTICS OF INDIAN DISABILITY STUDY CARRIED OUT IN THE COURSE OF $76^{\text {TH }}$ ROUND OF THE NSS (JULY-DECEMBER 2018)

These statistics are taken from the report of the survey of persons with disabilities in India conducted during NSS $76^{\text {th }}$ round (JulyDecember 2018). This report has been named as Persons with Disabilities in India NSS $76^{\text {th }}$ round (July-December 2018)-NSS Report No. 583(76/26/1), which is available free in the public domain. The $76^{\text {th }}$ round of Impaired Persons' survey comprised 8,992 First Stage Units (FSUs) (5,378 FSUs in rural areas and 3,614 FSUs in urban areas) covering 1,18,152 households (81,004 in rural areas and 37,148 in urban areas) and enumerating 5,76,569 persons $(4,02,589$ in rural areas and 1,73,980 in urban areas). In this sample, 1,06,894 individuals were questioned with disabilities $(74,946$ in rural areas and 31,948 in urban areas) [15]. The percentage of persons with disability for each State/Union Territories (UT) are tabulated in Table 1.

Table 1: The percentage of persons with disability for each State/Union Territories (UT)(11,15)

\begin{tabular}{|c|c|c|c|c|c|c|c|c|c|}
\hline \multirow{3}{*}{ State/UT } & \multicolumn{9}{|c|}{$\%$ of persons with disability } \\
\hline & \multicolumn{3}{|c|}{ Rural } & \multicolumn{3}{|c|}{ Urban } & \multicolumn{3}{|c|}{ Rural + Urban } \\
\hline & male & female & person & male & female & person & male & female & person \\
\hline Andhra Pradesh & 04.24 & 04.70 & 03.51 & 06.31 & 09.58 & 06.30 & 03.51 & 04.34 & 03.08 \\
\hline Arunachal Pradesh & 16.40 & 17.60 & 14.86 & 21.06 & 13.32 & 14.56 & 14.92 & 16.05 & 13.63 \\
\hline Assam & 4.15 & 4.66 & 3.59 & 8.91 & 10.92 & 8.20 & 3.78 & 4.28 & 3.31 \\
\hline Bihar & 2.47 & 4.39 & 2.48 & 6.39 & 8.10 & 5.13 & 2.32 & 4.05 & 2.30 \\
\hline Chhattisgarh & 8.08 & 8.25 & 6.69 & 8.18 & 10.38 & 7.78 & 6.87 & 7.05 & 5.74 \\
\hline Delhi & 11.68 & 20.13 & 9.65 & 8.79 & 8.91 & 7.41 & 8.57 & 8.72 & 7.23 \\
\hline Goa & 7.05 & 17.61 & 10.10 & 24.39 & 28.82 & 21.57 & 14.11 & 18.62 & 13.22 \\
\hline
\end{tabular}




\begin{tabular}{|c|c|c|c|c|c|c|c|c|c|}
\hline Gujarat & 4.61 & 5.01 & 3.86 & 9.05 & 6.13 & 6.28 & 4.66 & 3.89 & 3.45 \\
\hline Haryana & 5.59 & 6.01 & 4.19 & 8.41 & 8.30 & 7.13 & 4.65 & 4.85 & 3.69 \\
\hline Himachal Pradesh & 12.36 & 13.84 & 10.65 & 11.35 & 21.14 & 13.05 & 11.46 & 13.07 & 9.93 \\
\hline Jammu \& Kashmir & 9.63 & 6.79 & 5.22 & 12.35 & 12.13 & 10.50 & 8.01 & 5.89 & 4.72 \\
\hline Jharkhand & 5.79 & 7.34 & 5.36 & 6.79 & 11.62 & 7.42 & 4.73 & 6.29 & 4.49 \\
\hline Karnataka & 4.25 & 4.47 & 3.55 & 5.78 & 6.15 & 5.12 & 3.47 & 3.66 & 2.98 \\
\hline Kerala & 5.29 & 6.55 & 4.40 & 9.17 & 8.92 & 7.42 & 5.35 & 5.59 & 4.37 \\
\hline Madhya Pradesh & 3.29 & 4.50 & 3.10 & 5.43 & 12.50 & 7.09 & 2.82 & 4.90 & 2.98 \\
\hline Maharashtra & 3.81 & 3.50 & 3.03 & 3.81 & 4.76 & 3.40 & 2.91 & 2.84 & 2.36 \\
\hline Manipur & 10.65 & 10.43 & 8.26 & 9.37 & 10.53 & 7.80 & 8.05 & 8.04 & 6.28 \\
\hline Meghalaya & 10.16 & 10.33 & 7.80 & 10.44 & 20.22 & 9.42 & 8.58 & 9.27 & 6.72 \\
\hline Mizoram & 8.07 & 9.21 & 6.39 & 11.42 & 33.07 & 18.22 & 6.85 & 18.99 & 9.78 \\
\hline Nagaland & 10.03 & 11.41 & 7.97 & 10.89 & 11.25 & 6.27 & 7.82 & 8.67 & 5.93 \\
\hline Odisha & 3.98 & 5.09 & 3.52 & 7.83 & 11.44 & 7.01 & 3.56 & 4.65 & 3.16 \\
\hline Punjab & 12.32 & 13.55 & 8.79 & 6.75 & 10.40 & 7.08 & 8.97 & 9.59 & 6.40 \\
\hline Rajasthan & 3.89 & 4.72 & 3.58 & 16.17 & 8.29 & 10.03 & 4.93 & 4.11 & 3.66 \\
\hline Sikkim & 11.81 & 11.80 & 10.96 & 16.22 & 16.47 & 14.13 & 10.42 & 10.64 & 9.79 \\
\hline Tamil Nadu & 4.31 & 4.81 & 3.62 & 5.28 & 9.90 & 5.92 & 3.30 & 5.14 & 3.27 \\
\hline Telangana & 7.74 & 7.12 & 5.43 & 9.56 & 7.77 & 6.39 & 5.97 & 5.31 & 4.13 \\
\hline Tripura & 6.03 & 6.86 & 5.25 & 9.16 & 12.71 & 9.43 & 5.13 & 6.02 & 4.58 \\
\hline Uttarakhand & 9.34 & 9.54 & 7.46 & 11.47 & 18.91 & 9.26 & 7.73 & 8.61 & 6.19 \\
\hline Uttar Pradesh & 1.88 & 2.94 & 1.83 & 4.47 & 4.21 & 3.32 & 1.74 & 2.54 & 1.62 \\
\hline West Bengal & 3.06 & 4.62 & 2.91 & 6.64 & 6.17 & 5.34 & 2.96 & 3.74 & 2.62 \\
\hline A \& N Islands & 28.41 & 23.62 & 13.32 & 40.99 & 37.18 & 34.81 & 21.84 & 22.05 & 16.61 \\
\hline Chandigarh & 10.34 & 17.44 & 14.82 & 23.79 & 24.90 & 14.92 & 22.07 & 23.65 & 14.00 \\
\hline Dadra \& Nagar Haveli & 18.16 & 29.58 & 12.68 & 20.14 & 16.08 & 21.49 & 14.40 & 27.46 & 15.42 \\
\hline Daman \& Diu & 8.88 & 30.90 & 16.73 & 30.99 & 60.01 & 34.29 & 27.40 & 40.54 & 29.34 \\
\hline Lakshadweep & 23.16 & 26.12 & 3.38 & 14.87 & 20.55 & 11.40 & 13.51 & 18.79 & 10.34 \\
\hline Puducherry & 14.16 & 12.56 & 11.19 & 11.89 & 14.37 & 7.76 & 9.67 & 9.58 & 6.57 \\
\hline all-India & 0.94 & 1.19 & 0.82 & 1.82 & 1.99 & 1.47 & 0.84 & 1.03 & 0.72 \\
\hline
\end{tabular}

Below are some of the key results at the allIndia level obtained from this study.

\subsection{Disability frequency and occurrence}

Disability prevalence in India (percentage of individuals with disabilities in Indian population) was $2.2 \%$. In rural regions, it was 2.3 per cent and in metropolitan areas, 2.0 per cent. Disability occurrence was greater among males than among females. For males, disability prevalence was 2.4 percent, which was 1.9 percent for females. The incidence of disability in the community, that is, the amount of individuals whose incidence of disability (by birth or otherwise) existed
365 days prior to the date of the study, was 86 per 1,00,000 persons $[\mathbf{1 2}, \mathbf{1 5}]$.

\subsection{Level of literacy for people with disabilities}

52.2 per cent of people with disabilities aged 7 years and over were literate.For people with disabilities aged 15 years and over, 19.3 per cent have the maximum secondary school standard and higher.Among adults with disabilities between the ages of 3 and 35 , $10.1 \%$ attended the pre-school intervention program [17]. The number of people with disabilities between the ages of 3 and 35 who had ever studied in ordinary school was 
$62.9 \%$.For people who were not enrolled in ordinary school or enrolled in ordinary school but were not actually attending, the number of individuals aged 3 to 35 years with disability who were ever involved in special education was 4.1 per cent $[\mathbf{1 3}, \mathbf{1 5}$, 18 ].

\subsection{Living arrangement, care giver, aid/help receipt, disability certificate}

The number of individuals with disabilities lived alone was $3.7 \%$.For people with disabilities, 62.1 percent had caregivers, 0.3 percent of people with disabilities wanted caregivers but were not available, and no caregivers were required for another 37.7 percent of people with disabilities. The number of individuals with disabilities who obtained federal aid/help was 21.8 percent, 1.8 percent received non-governmental organizational aid/help, and another 76.4 percent did not obtain aid/help.For individuals with disabilities, 28.8 percent had disability certificates [15, 17-19].

\section{TREATMENTS OF INTELLECTUAL}

\section{DISABILITIES}

Federal legislation allows adolescents with intellectual disabilities throughout the educational system from ages 3-21 to access free assessments, independent learning, and professional training. Many jurisdictions have set up early intervention systems that evaluate and launch care programs for children under the age of three [22-22]. To educate retarded children in everyday life skills such as bathing and feeding themselves, several special schools are open. Various extracurricular programs and life skills that help youth develop self-esteem are taught to them. In early adulthood, training in independent living and work skills also begins. Slightly retarded people are expected to develop the abilities necessary to reside comfortably and have a profitable career. The intervention initiatives are well structured to support parents with children with intellectual disabilities build communication mechanisms to help parents cope with feelings of sadness [23-28].

\section{PREVENTING OR ADDRESSING INTELLECTUAL DISABILITIES}

Primary mitigation applies, according to the WHO, to a variety of approaches that minimize or remove the occurrence of public intellectual disability. By pursuing primary prevention, awareness of the causes of intellectual disability will further minimize cases by at least $25 \%$. There are several key preventive strategies that are defined as easy and complex.

\subsection{Initiatives at the stage of community}

In order to minimize the risk factors for intellectual disabilities, such as low birth 
weight and prematurity in the offspring, increasing the nutritional status of the population as a whole, in particular a girl child. The universal salt iodization is performed to avoid disorders of iodine deficiency and administration of folic acid pills to reduce the incidence of abnormalities in the neural tube $[\mathbf{2 9}, \mathbf{3 0}]$. Nutritional therapy can be supplied during pregnancy, with an emphasis on caloric and iron consumption. There should be complete vaccination of infants with BCG, polio, DPT, and MMR to reduce neurological injury and learning disability induced by multiple diseases. The incidence of maternal rubella syndrome may be eradicated through rubella immunization. Avoiding exposure during pregnancy to toxic chemicals and drugs, including tobacco, nicotine and cocaine can reduce the risk of intellectual disability. An enriching and stimulating culture for children should be given from early childhood for proper intellectual growth. At multiple stages, during the formative years, health education will contribute to healthier habits during pregnancy and child-rearing. The Early Intervention Program (EIP) will decrease the disorder's effect by early stimulation. Cases that may not be stopped by primary prevention are inevitably detected early in the Integrated Child Development
Scheme (ICDS) by neighborhood outreach services and Anganwadi Workers (AWW) [29, 31].

\subsection{Cutting edge processes}

These are usually more complex and costwise more costly than other alternatives. The defects of a foetus in the womb may be detected through prenatal diagnosis/screening, like amniocentesis and ultrasonography. Neonatal tests and prompt care for hyperthyroidism will typically avoid retardation and detect these conditions early [32-34]. As a treatment for undernourished youth, developmental screening is an important factor for diagnosis. An innovative approach is molecular genetics for the identification of hereditary and other diseases [15]. It is possible to diagnose the presence of Downs' syndrome by a blood examination on the mother during early pregnancy [3538].

\section{MINISTRY OF LABOUR'S} INITIATIVES, GOVERNMENT OF INDIA

There are 47 Special Work Exchanges and 914 grueling work exchanges that address the employment requirements of disabled job seekers. In the standard train fare, preferential allocation of telephone booths, preferential allocation of property and building sites by housing boards and local 
planning agencies, seventy-five percent discounts may be received for disabled citizens. Parents will provide choice posting of federal service in the case of cerebral palsy and intellectual disability, and 100 percent support for voluntary organizations to build corporate structures and educate personnel. But, for those with disabilities, there is no unemployment allowance/social insurance or any other security services available $[2,10,16,39]$.

\section{COVID-19 AND PEOPLE WITH INTELLECTUAL DISABILITY}

For a variety of causes, like physical wellbeing issues, social circumstances, and deficiencies of comprehension, people with intellectual disability are more susceptible to infection. People with intellectual disability have a greater rate of comorbid physical conditions, and their life span is shorter than the general population, with an overall mortality rate of 3.18 [40, 41]. Heritable cardiovascular, metabolic, or respiratory abnormalities may affect people with intellectual disability and neurological mutations. In people with intellectual disabilities, particularly those with Down syndrome, respiratory infections are the leading cause of death [42]. Obesity is more common in people with intellectual disability, increasing their chances of developing serious COVID-19 infections. People with intellectual disability have a greater incidence of physical and behavioral illnesses than the general public [43].

People with developmental disabilities reside in a variety of environments that are essentially congregated, such as nursing homes, assisted housing placements, or medical in-patient treatment. Many people live with elderly parent caregivers whose wellbeing is often jeopardized. People with intellectual disability are more likely to have trouble fighting for themselves through pandemics and depend on others to keep them healthy from infection [44]. For those with moderate intellectual disability who live alone in the neighborhood, their cognitive capacity can make it difficult for them to stick to public health interventions such as self-isolation, hand washing, or physical separation from others. Such social behavioral expectations can be challenging to comprehend and enforce, especially for those with behavioral issues such as spitting, which can put other individuals with intellectual disability and their caregivers at danger [45]. Caregivers can find it challenging to help individuals for whom restricting their restricted freedoms may be troublesome, especially when their personal habits have been disrupted, such as 
attending daily day-time activities. Because of a shift of habits, self-isolation and physical distancing will increase the stress level of people with autism [46]. The amount of knowledge about COVID-19 in the media and on social media could cause them to become too concentrated and, as a result, overloaded. Such behavior can increase their anxiety and paranoid thought, causing difficulties in their behavior and reducing their capacity to engage in social distancing behaviors $[47,48]$.

\section{CONCLUSION}

Disability prevalence in India (percentage of individuals with disabilities in Indian population) was $2.2 \%$. In rural regions, it was 2.3 per cent and in metropolitan areas, 2.0 per cent. Disability occurrence was greater among males than among females. For males, disability prevalence was 2.4 percent, which was 1.9 percent for females. The incidence of disability in the community, that is, the amount of individuals whose incidence of disability (by birth or otherwise) existed 365 days prior to the date of the study, was 86 per 1,00,000 persons.

Depending on their degree of disability, there is a requirement to include an intervention service for children with intellectual disabilities for social purposes. This children will become self-sufficient members of our community if they are well educated and trained. Since we are people of the greatest democracy, fairness includes a government to take account of the interests of any part of the community. By progressive shifts in social understanding, perceptions and values towards intellectual disability, it is the right of individuals with intellectual disabilities to lead their lives with integrity and dignity. On humanitarian grounds, to make their lives worth living, education must be provided to these unfortunate children. The separate provisions for the schooling of children with intellectual disabilities ought to be made, when and if we do not pay for their education, their capacity would stay undeveloped, resulting in a great loss of human capital and being a responsibility to community. They can experience issues with adaptation that may eventually lead them to neurotic actions. It is possible to teach and develop them in adaptive behavior skills by systematic measures and utilizing proper techniques. Training for people with intellectual disabilities is targeted at preparing them for social life and enabling them to develop the knowledge required to lead autonomous or less reliant lives. Particular focus has been imposed in recent years on the need to help these people learn some social skills in order to train them for 
social life. In order to help children boost self-esteem and extra-curricular opportunities and develop occupational skills, special schools provide education in technical skills such as dressing and washing, etc.

Children with disabilities are unwilling to play certain tasks, such as interacting and socializing with others, and also taking care of themselves in certain cases. They face difficulties with basic tasks, such as feeding, washing, chatting and walking. They are especially vulnerable to stress, weak self-image, and a loss of faith in themselves. There is a considerably slower speed at which they develop and comprehend stuff than those of kids without developmental disabilities. It is challenging for these people to understand, because the time it requires to train them is far longer than it takes to educate someone without developmental disabilities. In the design of social skills educational interventions, language skills training, reading and writing training, music activities, meditation sessions, dance activities, art and craft opportunities, and physical fitness programs for adolescents with intellectual disabilities, future researchers may emphasize this. The survey findings are beneficial to numerous stakeholders such as the National Institution for the Transforming India (NITI Aayog), the
Ministry of Social Justice and Empowerment, the Ministry of Health and Family Welfare, various Institutes/Organizations, the Economic and Social Commission for Asia and the Pacific (ESCAP) of the United Nations and various researchers.

$$
\text { Individuals with intellectual }
$$

disability experiences with the pandemic must be elicited in order to comprehend the effects on their life and how they have saved themselves from infections. It's important that we learn from the pandemic on how to safeguard individuals with intellectual disability, both because of their intrinsic susceptibility to illness and because of the social repercussions of the pandemic's management steps. When the time arrives to assess the pandemic's progress, it's important that individuals with intellectual disability and their caregivers are not overlooked in order to guarantee that they are prepared to deal with similar situations in the future.

\section{List of Abbreviations}

NITI Aayog: National Institution for the Transforming India

ESCAP: Economic and Social Commission for Asia and the Pacific EIP: $\quad$ Early Intervention Program 
ICDS: Integrated Child Development

Scheme

UT: Union Territories

FSUs: $\quad$ First Stage Units

PWD Act: Rights of Persons with

Disabilities Act

NSC: National Statistical

Commission

NSSO: National Sample Survey

Organization

NSS: National Service Scheme

NSO: National Statistical Office

WHO: $\quad$ World Health Organization

\section{Acknowledgments}

Conflicts of Interests

Declared none

\section{REFERENCES}

1. Kalgotra R, Warwal JS. Intellectual Disability in India: An overview. J Disabil Stud. 2017;3(1):15-22.

2. Chavan B, Rozatkar A. Intellectual disability in India: Charity to right based. Vol. 56, Indian Journal of Psychiatry. 2014. p. 113-6.

3. Girimaji SC, Srinath S. Perspectives of intellectual disability in India: Epidemiology, policy, services for children and adults. Vol. 23, Current Opinion in Psychiatry. 2010. p. 441-6.

4. Ganesh KS, Das A, Shashi JS. Epidemiology of disability in a rural community of Karnataka. Indian $\mathrm{J}$ Public Health. 2008;52(3):125-9.

5. Mandal PK, Chakrabarty D, Ghosh P, Manna N, Mallik S, Chatterjee C, et al. Geriatric disability and associated risk factors: A community based study in a rural area of West Bengal, India. Iran J Med Sci. 2010;35(1):27-32.

6. Girimaji SC. Intellectual disability in India: the evolving patterns of care. Int Psychiatry. 2011;8(2):29-31.

7. Verma RK, Kishore MT. Needs of Indian parents having children with intellectual disability. Int J Rehabil Res. 2009;32(1):71-6.

8. Ilyas M, Mir A, Efthymiou S, Houlden H. The genetics of intellectual disability: Advancing technology and gene editing. Vol. 8, F1000Research. 2019.

9. Iezzoni LI, Matulewicz H, Marsella SA, Warsett KS, Heaphy D, Donelan K. Collaborative design of a health care experience survey for persons with disability. Disabil Health J. 2017;10(2):231-9.

10. Simpson N, Mizen L, Cooper SA. Intellectual disabilities. Vol. 48, Medicine (United Kingdom). 2020. p. 732-6.

11. Boot $\mathrm{FH}$, Ghosh R, Dinsmore JG, 
Maclachlan M. Views and experiences of people with intellectual disabilities to improve access to assistive technology: Perspectives from India. Disabil CBR Incl Dev. 2020;31(4):4065.

12. Narayan J. Empowering persons with intellectual disability. In: Disability Inclusion and Inclusive Education. 2020. p. 63-82.

13. Wongsawat S. Predicting factors for quality of life of elderly in the rural area. Int J Arts Sci. 2017;09(04):36371.

14. Pal CP, Singh P, Chaturvedi S, Pruthi KK, Vij A. Epidemiology of knee osteoarthritis in India and related factors. Indian $\mathrm{J}$ Orthop. 2016;50(5):518-22.

15. The National Statistical Office (NSO) $\mathrm{M}$ of S and PI. NSS report no. 583: Persons with Disabilities in India NSS 76th round (July - December 2018) [Internet]. 2018. Available from: https://pib.gov.in/newsite/PrintRelease .aspx? relid $=194923$

16. Sample N, Organisation S, Government PI. National Sample Survey Organisation Ministry of Statistics and Programme Implementation Government of India
September 2002. 58th Round [Internet]. 2002;478(478). Available from:

http://mospi.nic.in/sites/default/files/p ublication_reports/507_final.pdf

17. Rao LG. Education of persons with intellectual disabilities in India. Vol. 50, Salud Publica de Mexico. 2008.

18. Bhattacharyya R, Ghoshal MK, Sanyal D. Magnitude of problem of persons having intellectual disability its impact on parents and their unmet needs in Indian subcontinent. Bengal $\mathrm{J}$ Psychiatry. 2015;1-6.

19. Gal I, Weisberg-Yosub P, Shavit M, Doron I. Complaints on health services: A survey of persons with disabilities. J Disabil Policy Stud. 2010;21(3):181-8.

20. Behrani P, Deka DB. An Overview on Issues Among Individuals With Intellectual Disability in India. In 2019. p. 166-85.

21. Sankar R. Progress and challenges in the understanding of early epileptic encephalopathies. No To Hattatsu [Internet]. 2016;48:S110. Available from:

https://www.embase.com/search/result s?subaction=viewrecord\&id=L619996 609\&from=export 
22. Jauhari $\mathrm{P}$, Boggula $\mathrm{R}$, Bhave A, Bhargava R, Singh C, Kohli N, et al. Aetiology of intellectual disability in paediatric outpatients in Northern India. Dev Med Child Neurol. 2011;53(2):167-72.

23. Rao LG, Suryaprakasam B. Effective Teamwork in Special Schools for Children with Intellectual Disabilities in India. J Policy Pract Intellect Disabil. 2004;1(2):79-87.

24. Robertson J, Chadwick D, Baines S, Emerson E, Hatton C. People with intellectual disabilities and dysphagia. Disabil Rehabil. 2018;40(11):134560.

25. Edwardraj S, Mumtaj K, Prasad JH, Kuruvilla A, Jacob KS. Perceptions about intellectual disability: A qualitative study from Vellore, South India. J Intellect Disabil Res. 2010;54(8):736-48.

26. Kishore MT, Nizamie A, Nizamie SH, Jahan M. Psychiatric diagnosis in persons with intellectual disability in India. J Intellect Disabil Res. 2004;48(1):19-24.

27. Lakhan R, Ekúndayò O. Important research priorities in intellectual disability in India: A public health perspective. Vol. 8, Journal of
Neurosciences in Rural Practice. 2017. p. $150-1$.

28. May P, Lombard Vance R, Murphy E, O’Donovan MA, Webb N, Sheaf G, et al. Effect of deinstitutionalisation for adults with intellectual disabilities on costs: A systematic review. Vol. 9, BMJ Open. 2019.

29. Roy A, Roy M, Clarke D. Causes and Prevention of Intellectual Disabilities. In: The Psychiatry of Intellectual Disability. 2020. p. 19-28.

30. Neil N, Liesemer K. Early Behavioral Intervention for Young Children with Intellectual and Developmental Disabilities. Vol. 7, Current Developmental Disorders Reports. 2020. p. 139-48.

31. Araten-Bergman T, Bigby C. Violence Prevention Strategies for People with Intellectual Disabilities: A Scoping Review. Aust Soc Work. 2020;1-16.

32. Schijven EP, Hulsmans DHG, VanDerNagel JEL, Lammers J, Otten $\mathrm{R}$, Poelen EAP. The effectiveness of an indicated prevention programme for substance use in individuals with mild intellectual disabilities and borderline intellectual functioning: results of a quasi-experimental study. Addiction. 2021;116(2):373-81. 
33. Hale L, Vollenhoven E, Caiman L, Dryselius A, Buttery Y. Feasibility and acceptability of Otago Exercise Programme and Prevention of Falls for Adults with Intellectual Disability: A multiple case study design. Int J Ther Rehabil. 2019;26(6).

34. Oliver-Africano P, Murphy D, Tyrer P. Aggressive behaviour in adults with intellectual disability: Defining the role of drug treatment. CNS Drugs. 2009;23(11):903-13.

35. Alexander $\mathrm{M}$, Benoit J, Barth J, Breech LL, Schwartz BI. Outcomes of Intrauterine Device Use in Young Women With Physical and Intellectual Disabilities. J Pediatr Adolesc Gynecol. 2016;29(2):163-4.

36. Barger E, Wacker J, Macy R, Parish S. Sexual assault prevention for women with intellectual disabilities: A critical review of the evidence. Vol. 47, Intellectual and Developmental Disabilities. 2009. p. 249-62.

37. Yen CF, Loh CH, Lin JD. Prevention of mental health problems in people with intellectual disability. Vol. 22, Current Opinion in Psychiatry. 2009. p. 447-51.

38. Grosse SD, Van Vliet G. Prevention of intellectual disability through screening for congenital hypothyroidism: How much and at what level? Vol. 96, Archives of Disease in Childhood. 2011. p. 374-9.

39. Lakhan R, Ekúndayò OT. National sample survey organization survey report: An estimation of prevalence of mental illness and its association with age in India. J Neurosci Rural Pract. 2015;6(1):51-4.

40. Courtenay K, Perera B. COVID-19 and people with intellectual disability: Impacts of a pandemic. Vol. 37, Irish Journal of Psychological Medicine. 2020. p. 231-6.

41. Redquest BK, Tint A, Ries H, Lunsky Y. Exploring the experiences of siblings of adults with intellectual/developmental disabilities during the COVID-19 pandemic. J Intellect Disabil Res. 2021;65(1):1-10.

42. Glover G, Williams R, Heslop P, Oyinlola J, Grey J. Mortality in people with intellectual disabilities in England. J Intellect Disabil Res. 2017;61(1):62-74.

43. O'Leary L, Hughes-McCormack L, Dunn K, Cooper SA. Early death and causes of death of people with Down syndrome: A systematic review. J Appl Res Intellect Disabil. 
2018;31(5):687-708.

44. Perera B, Audi S, Solomou S, Courtenay K, Ramsay H. Mental and physical health conditions in people with intellectual disabilities: Comparing local and national data. $\mathrm{Br}$ J Learn Disabil. 2020;48(1):19-27.

45. Embregts PJCM, van den Bogaard KJHM, Frielink N, Voermans MAC, Thalen M, Jahoda A. A thematic analysis into the experiences of people with a mild intellectual disability during the COVID-19 lockdown period. Int J Dev Disabil. 2020;

46. Heslop P, Glover G. Mortality of People with Intellectual Disabilities in England: A Comparison of Data from Existing Sources. J Appl Res Intellect Disabil. 2015;28(5):414-22.

47. Palacio-Ortiz JD, Londoño-Herrera JP, Nanclares-Márquez A, RobledoRengifo P, Quintero-Cadavid CP. Psychiatric disorders in children and adolescents during the COVID-19 pandemic. Vol. 49, Revista Colombiana de Psiquiatria. 2020. p. 279-88.

48. Tromans S, Chester V, Harrison H, Pankhania P, Booth H, Chakraborty N. Patterns of use of secondary mental health services before and during
COVID-19 lockdown: observational study. BJPsych Open. 2020;6(6). 